\title{
The Statistics of Equatorial Spread-F and Effects on Critical Frequency at Chumphon, Thailand
}

\author{
Phimmasone Thammavongsy ${ }^{1}$, Pornchai Supnithi ${ }^{1}$, Watid Phakphisut ${ }^{1}$, Kornyanat \\ Hozumi $^{2}$, Takuya Tsugawa ${ }^{2}$, and Kallaya Bannop ${ }^{3}$
}

\author{
${ }^{1}$ Faculty of Engineering, King Mongkut's Institute of Technology Ladkrabang, Bangkok, 10520, Thailand. \\ ${ }^{2}$ Space Environment Laboratory, National Institute of Information and Communications Technology, Nukuitita, \\ Koganei, Tokyo 184-8795, Japan. \\ ${ }^{3}$ Thalang Technical College, 215 Moo 5 Thepkrasettree District, Thalang, Phuket, 83110, Thailand. \\ *Corresponding author: pornchai.su@kmitl.ac.th
}

\begin{abstract}
This work presents the study of equatorial spread-F (ESF) characteristics based on the occurrence percentages and durations during the maximum solar activity of the $24^{\text {th }}$ solar cycle at Chumphon station (CPN), Thailand. The statistics of ionogram data covering all months in 2014 are obtained from the ionosonde station. The effects of ESFs on communication signals are denoted by comparing the critical frequency of F2 layer (foF2) with ESFs. The results show the high ESF occurrence percentages in the equinoctial months and some months during the solstices.

Keywords: ESF probability, ESF duration, critical frequency, maximum solar activity
\end{abstract}

\section{INTRODUCTION}

Equatorial spread-Fs (ESFs) indicate the nighttime ionospheric irregularity related to the equatorial plasma bubbles (EPBs). They are often shown as the spreading of traces on ionogram images. In addition, the ESFs may impact the integrity of the high frequency (HF) and the satellite signals such as the Global Navigation Satellite Systems (GNSS). Therefore, the study and prediction of ESF phenomenon are necessary for better understanding and mitigation of the effects.

In the previous works, ESFs are derived from the ionogram data based on the frequency modulation/continuous waves $(\mathrm{FM} / \mathrm{CW})$ ionosonde at the equatorial station. The scale size of $F$ layer plasma structure ranges from decameters to kilometers [1]. The occurrences of ESFs are caused by the fast recombination in $\mathrm{F}$ layer after sunset leading to the depletion of plasma bubble density rising up from bottomside of $\mathrm{F}$ layer and penetrating the tope side of $\mathrm{F}$ layer [2]. The ESFs are influenced from complex processes which compose of electrodynamic mechanisms within the ionosphere. The basic mechanism that plays a significant role on the ESF onset is the generalized Rayleigh-Taylor (R-T) instability, particularly, a rapid lifting of equatorial $F$ layer is driven by the evening pre-reversal electric field enhancement (PRE) [3]. The statistics of ESF data from longitudinal stations are analyzed and utilized to create the ESF prediction model in Brazil. The derived ESF model is now available in International Reference Ionospheric (IRI) model [4]. The occurrences of ESFs are observed frequently over the equatorial regions. In that the development of ESF occurrences starts at low latitudes and extends to high latitudes in Thailand. Additionally, the rapid rising of h'F monthly mean values is confirmed as a role of the PRE on the ESF onset [5]. The ESFs are verified to occur when PREs are above the given threshold, furthermore, the enhancement of ESF probability increases approximately linearly with the PRE and it is also characterized as function of PRE magnitude [6]. The temporary change of h'F is analyzed and referred to be associated with a seeding amplitude of gravity wave (GW) as a trigger of the ESF onset [7]. The amplitude of the GW seed perturbation is investigated as a critical factor in indicating ESF occurrence. [8]. As ESFs are related to EPBs, the EPBs are studied by using an all-sky imaging depending on seasonal variations during the 23rd-24th solar cycle over Brazil region. This study denotes that EPB occurrences in all seasons correlate positively with solar activity variation such as F10.7 index [9]. The machine learning plays an important role on the space field such the prediction model of the foF 2 parameter is established using the neural networks. The functionality of prediction model is able to estimate the near-real time value of foF2 depending on the recent past observations of foF 2 from the four stations must be available in real time [10]. The neural network is successfully applied to the prediction model of the probability of spread-F occurrence [11]. In addition, the development of foF2 forecast using neural network is improved in terms of initialing the weights of the network model by using the genetic algorithm [12]. Therefore, the studies of ESF and its effects lead to further developments and solutions which depend on the computer science.

In this study, the ESF occurrence percentage and duration are analyzed during peak solar activity of the 24th solar cycle at CPN station, Thailand. The seasonal ESF characteristics are based on the F10.7 solar flux index. Moreover, the critical frequency of F2 layer is plotted to show the effects of ESF on the high frequency signals.

\section{METHODOLOGY}

The ionospheric monitoring so called the frequency modulation/continuous waves $(\mathrm{FM} / \mathrm{CW})$ ionosonde has been made at Chumphon (CPN) station which is close to the magnetic equator in Southeast Asia. The recorded ionogram data is considered at every 15 minutes from 18.00 LT to 06.00 LT for each day in 2014. The concerned 
absence of RSF occurrences, respectively. As shown in Fig. 1 (a) - (b), the observed ionogram images respectively demonstrate the normal trace without ESF and the spreading of trace is diffused by the equatorial irregularity so called ESF

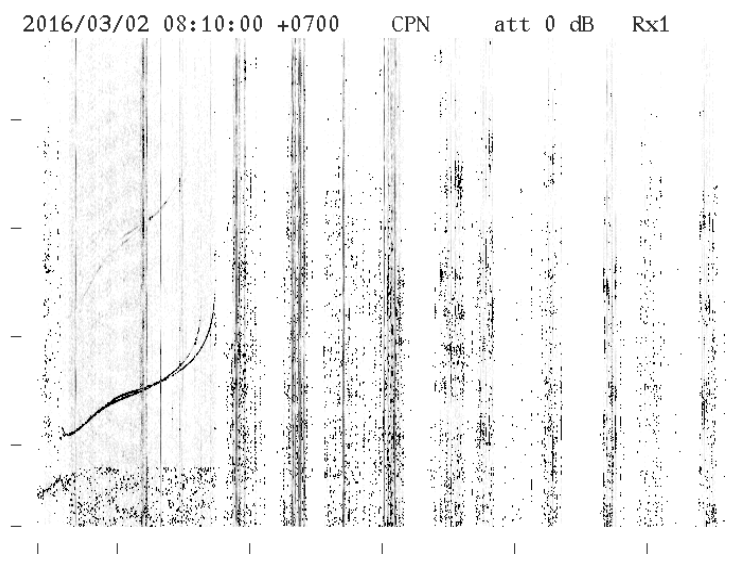

(a)

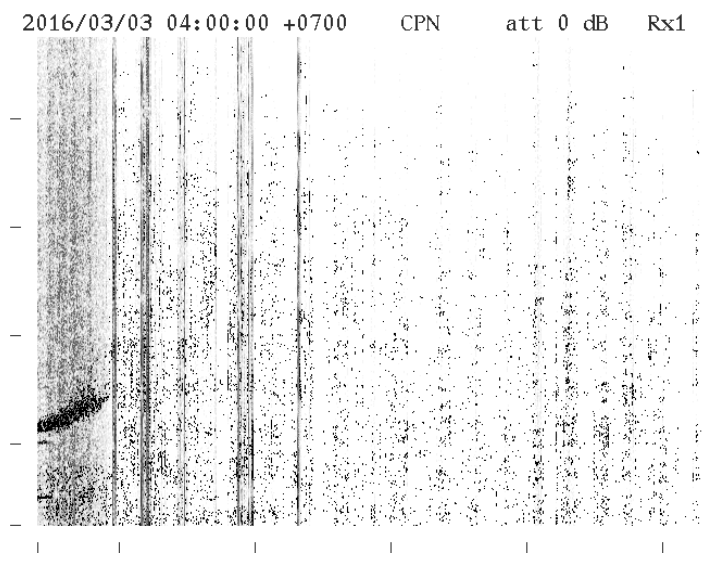

(b)

Figure 1. The ionogram images of (a) a normal ionogram trace and (b) the spreading trace is called ESF.

The statistics of RSF variations are analyzed in terms of the monthly percentage and duration of RSF occurrences. The monthly value of F10.7 solar flux index is obtained from Space Weather Prediction Center (SWPC), National Oceanic and Atmospheric Administration (NOAA) on ftp://ftp.swpc.noaa.gov/pub/warehouse/2014/ as shown in Fig. 2. It is applied to demonstrate the influence of solar activity with RSF occurrence during the study case of the peak solar activity of 24th solar cycle. The RSF duration is observed by following the continuous occurrences of
RSF against the frequency of its duration in each month. The RSF occurrence percentage is calculated as

$$
\% R S F=\frac{\sum_{i=1}^{N} R S F_{i}}{N} \times 100 .
$$

where, \%RSF is the percentage of occurrence of RSF, $R S F_{i}$ represents the occurrence of RSF at time $i$ and $N$ is the total number of observed data points

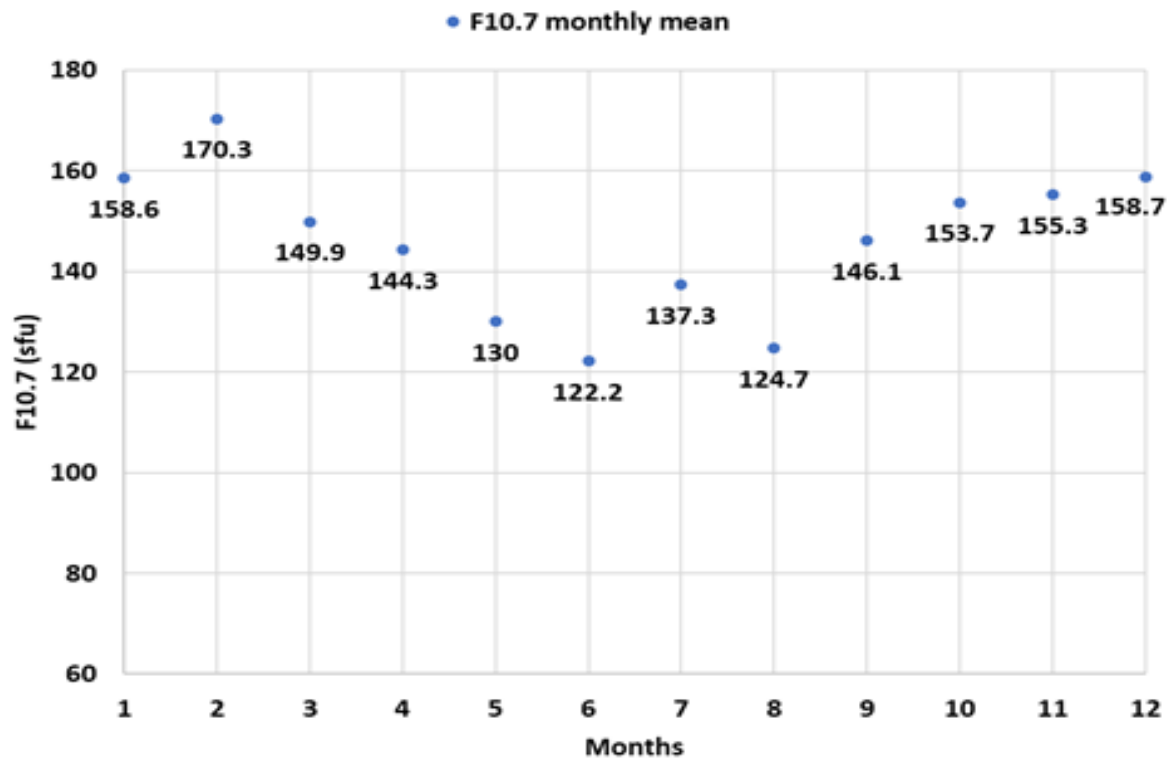

Figure 2. F10.7 monthly mean values in 2014. 


\section{RESULTS AND DISCUSSION}

From Fig. 3, the highest percentages of RSF occurrences occur in equinoctial months including March, April, February, October and September, respectively. In contrast, the low percentage is seen in solstice months such as November, January, December, May and August, respectively. Note that there are missing data in June and July. The high percentages of RSF occurrences are between $40 \%$ and $80 \%$ during $20.00 \mathrm{LT}$ to $04.00 \mathrm{LT}$ in March equinoxes. The highest percentage is above $80 \%$ in March with 149.9sfu of F10.7 solar flux. The peak value of F10.7 is 170.3 sfu in February and RSF occurrence rate is below $70 \%$. In September equinoxes, the probability of RSF occurrence rate is above $20 \%$ and below $80 \%$ during 20.00LT to 02.00LT in September and October. In contrast, the observed RSF percentage is below 20\% in August as shown in Fig. 3. This minimum RSF rate corresponds positively to $124.7 \mathrm{sfu}$ as shown in Fig. 2. In general, the tendency of RSF occurrence rate is proportional to the F10.7 solar flux for the September equinoxes. In December solstices, the RSF occurrence rate is below $40 \%$ from 19.00LT to 06.00LT in December and January, 19.00LT to 05.00LT in November. The highest percentages of RSF occurrences are more than $40 \%$ and below $70 \%$ during 20.00LT to $22.00 \mathrm{LT}$ in November corresponding to 155.3sfu of F10.7 solar flux. In June solstices, only the data in May are available and the RSF occurrence rate is below $20 \%$ during $20.00 \mathrm{LT}$ to $05.00 \mathrm{LT}$ with $130 \mathrm{sfu}$. Thus, the observed RSF occurrence rate shows it is related to F10.7 solar flux in solstice months. For equinoctial months, the variations of RSF occurrence rates are influenced by the seasonal variations and F10.7 solar flux. Note that the RSF occurrence rate is not influenced by the peak value of F10.7 during February
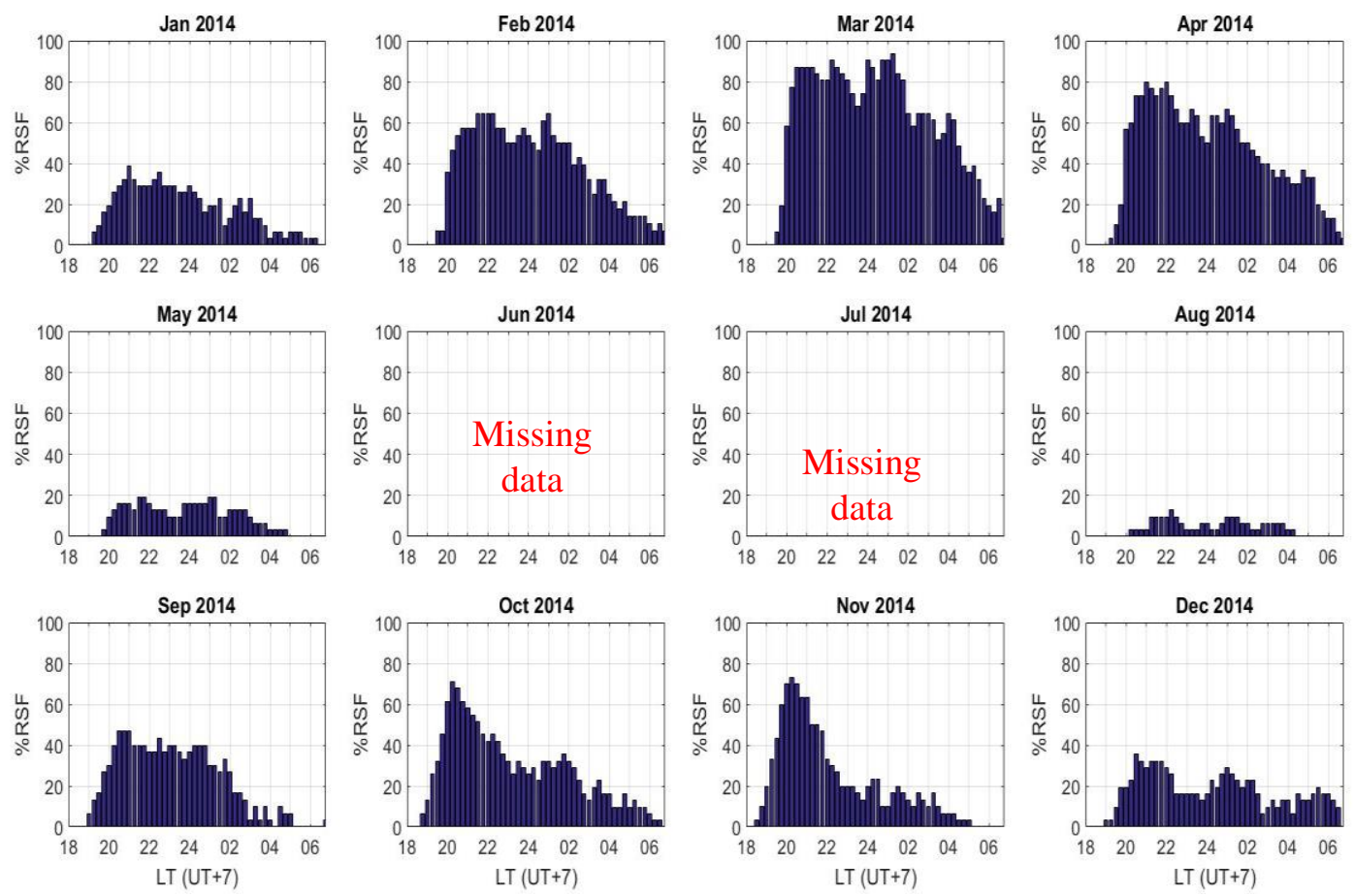

Figure 3. RSF occurrence percentages in each month during 2014 at CPN station.

Fig. 4 shows the duration of RSF occurrences against the frequency of RSF duration in each month in 2014. The RSF durations are between 15 minutes to 9 hours. Most of the observed durations of RSF occurrences are below 7 hours for both equinoctial and solstice months as illustrated in Fig 4. RSF duration is frequently observed between 15 minutes to 5 hours in equinoctial months, higher than in solstice months, particularly, in February, March, April, and October. These observed durations imply that the levels of F10.7 solar flux values influence the frequency of RSF durations. Then this verifies specifically the long durations corresponding to each level of F10.7 solar flux 

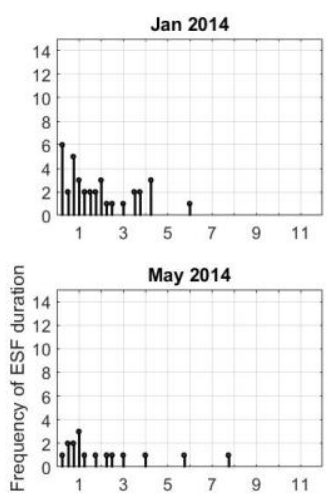

Sep 2014

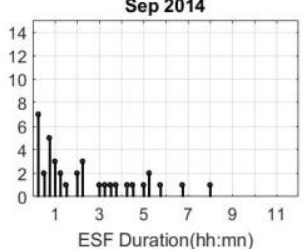

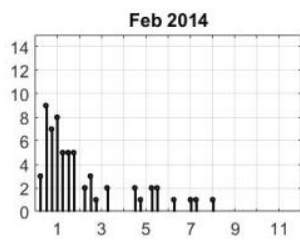

Jun 2014

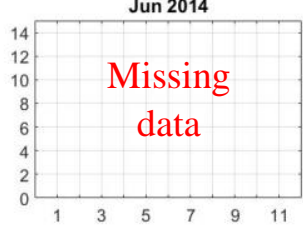

Oct 2014

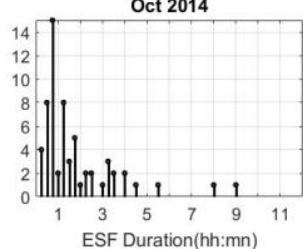

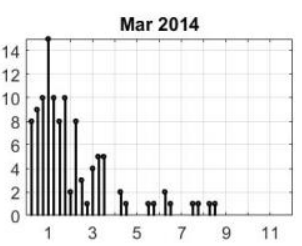

Jul 2014

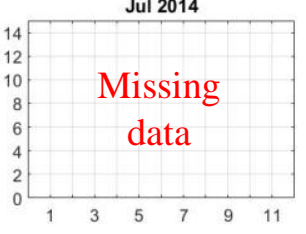

Nov 2014

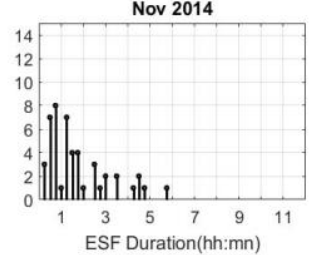

Apr 2014

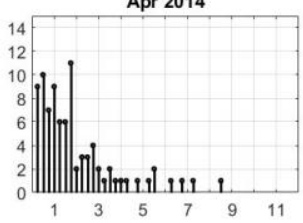

Aug 2014

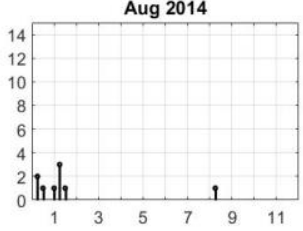

Dec 2014

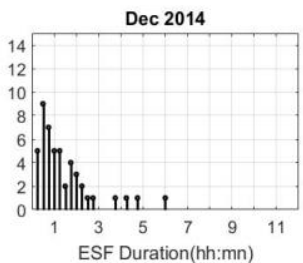

Figure 4. RSF duration in each month during 2014 at CPN station.

As shown in Fig. 5, the instances of the observed foF2 values (blue line), the median values of foF2 (red dots) are calculated using previous 15-day data and the observed RSF occurrence (black bar). Error bar represents 30\% available of foF2 values. The effects of RSF occurrences lead to the disappearance of foF2 values as shown in Fig. 5(a)-(d) and, moreover, it is a cause of the frequency outage.

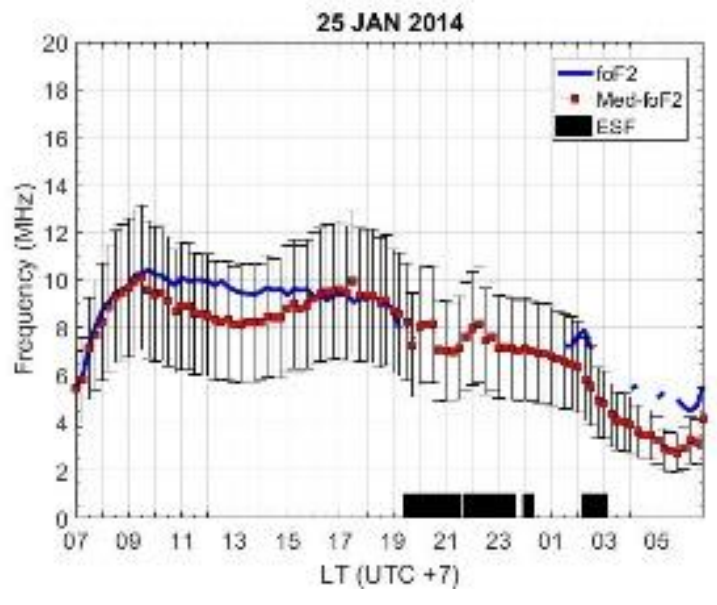

(a)

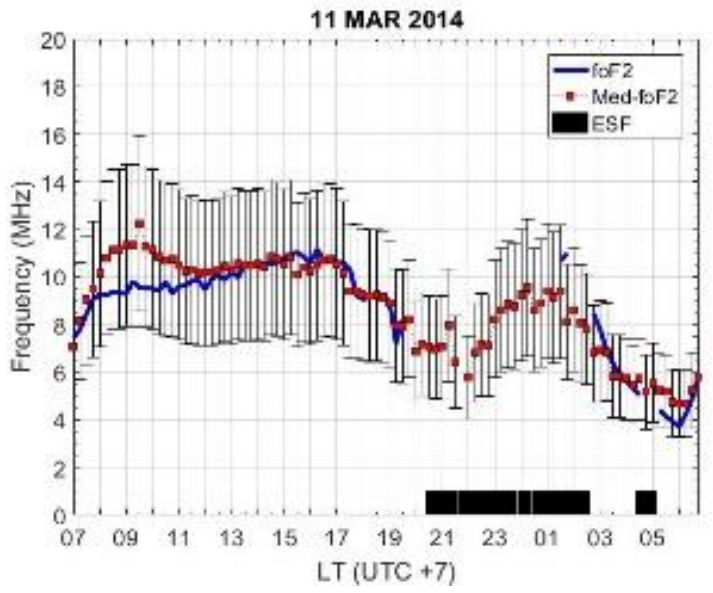

(c)

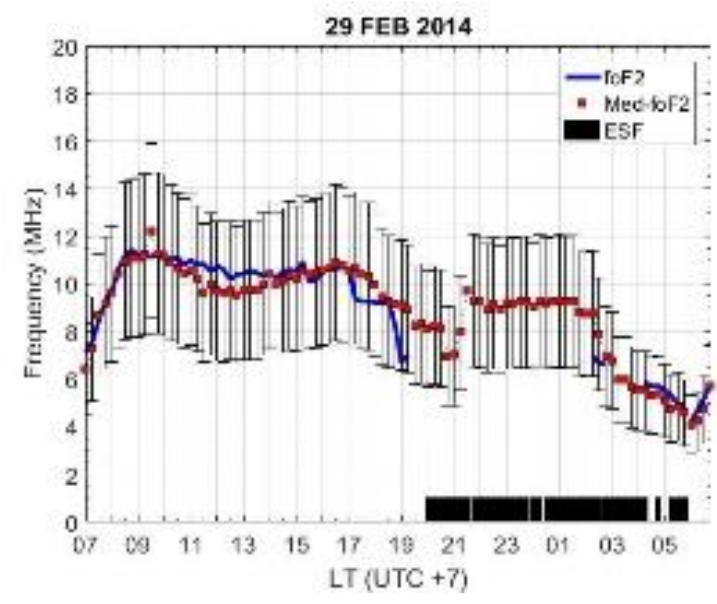

(b)

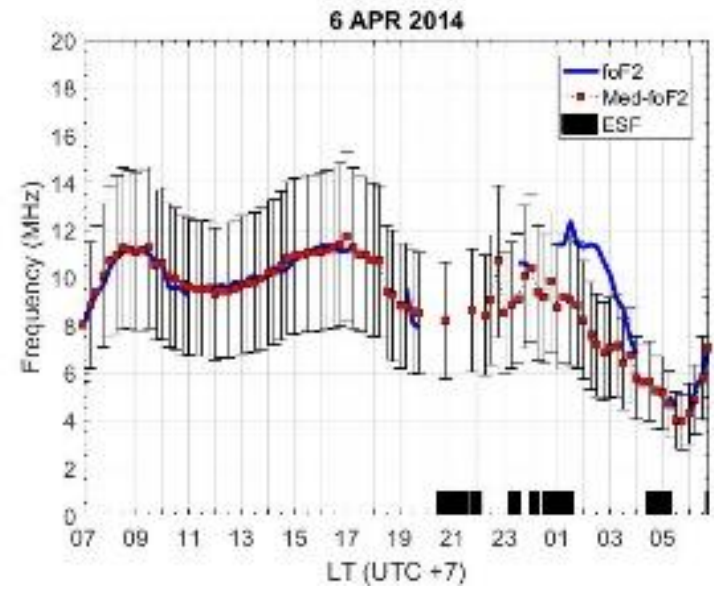

(d)

Figure 5. The observed foF2 and 15-day median values of foF2 with RSF occurrence at CPN station. 


\section{CONCLUSIONS}

In this study, the two statistical characteristics of RSF are used to analyze and verify the characteristics of RSF occurrences during the peak solar activity of the $24^{\text {th }}$ solar cycle over equatorial CPN region. These two features of RSF occurrence rates indicate that the RSF occurrence rates are associated with the solar activity. Also, the duration of RSF occurrences has a good relationship with solar activity as well. The high percentages of RSF occurrences are mostly observed to be $40 \%$ to $80 \%$ in the equinoctial months. The high RSF durations are frequently seen in equinoctial months. The RSF occurrence rates below $40 \%$ are observed in solstice months, except in November with the percentage above $40 \%$ during $20.00 \mathrm{LT}$ to $22.00 \mathrm{LT}$. Therefore, the variations of RSF occurrences are investigated to be related with the seasonal variations and the effects of RSF on $f o F 2$ parameter need to be further considered.

\section{ACKNOWLEDGMENT}

This work is partially supported from King Mongkut's Institute of Technology Ladkrabang under grant \#A118-0161-005. In addition, this work is the output of the ASEAN IVO (http://www.nict.go.jp/en/asean_ivo/index.html) project "GNSS and Ionospheric Data Products for Disaster Prevention and Aviation in LowLatitude Regions" and financially supported by NICT (http://www.nict.go.jp/en/index.html). Also, we would like to express our gratitude to NOAA for the provision of data.

\section{REFERENCES}

[1] H.G. Booker and H.W. Wells, Scattering of radio waves in the $\mathrm{F}$ region of the ionosphere., Terr. Magn. Atmos. Electr., 43, 249, 1938.

[2] D.L. Hysell, An overview and synthesis of plasma irregularities in equatorial spread F. J. Atmos. Sol. Terr. Phys. 62, 1037-1056, 2000.

[3] M.A. Abdu, Outstanding problems in the equatorial ionosphere-thermosphere system relevant to spread F. J. Atmos. Terr. Phys. 63, 869-884, 2001.

[4] M. Abdu, J. Souza, I. Batista, and J. Sobral, Equatorial spread $\mathrm{F}$ statistics and empirical representation for IRI: A regional model for the Brazilian longitude sector., Advances in Space Research, 31, 703-716, 2003.

[5] S. Rungraengwajiake, P. Supnithi, T. Tsugawa, T. Maruyama, and T. Nagatsuma, The variation of equatorial spread-F occurrences observed by ionosondes at thailand longitude sector., Advances in Space Research, 52, 1809-1819, 2013.

[6] C.S. Huang, Effects of the postsunset vertical plasma drift on the generation of equatorial spread $F$. Progress in Earth and Planetary Science, 5, 1-15, 2018.

[7] M.A. Abdu, E. Kherani, I. Batista, E. de Paula, D. Fritts, and J. Sobral, Gravity wave initiation of equatorial spread F/plasma bubble irregularities based on observational data from the spreadFEx campaign., Ann. Geophys, 27, 2607-2622, 2009.

[8] G. Manju, M. Madhav Haridas, and R. Aswathy, Role of gravity wave seed perturbations in ESF day-to-day variability: A quantitative approach., Advances in Space Research, 57, 1021-1028, 2016.

[9] E. Agyei-Yeboah, I. Paulino, A.F. de Medeiros, R.A. Buriti, A.R. Paulino, P. Essien, S.O. Lomotey, H. Takashi and C. M. Wrasse, Seasonal variation of plasma bubbles during cycle 23-24 over The Brazilian equatorial region., Advances in Space Research, 19, 1-17, 2019.

[10] E.O. Oyeyemi, L.A. McKinnell, A.W.V. Poole, Near-real time foF2 predictions using neural networks., Journal of atmospheric and Solar-Terrestrial Physics, 68, 1807-1818, 2006.

[11] L.A. McKinnell, M.W. Paradza, P.J. Cilliers, M.A. Abdu, J.R. de Souza, Predicting the probability of occurrence of spread-F over Brazil using neural networks., Advances in Space Research, 46, 1047 $1054,2010$.

[12] J. Zhao, X. Li, Y. Liu, X. Wang, C. Zhou, Ionospheric foF2 Disturbance Forecast Using Neural network Improved by Genetic Algorithm., Advances in Space Research, 19, 4003-4014, 2019.

[13] N. Wakai, H. Ohyama and T. Koizumi, Manual of Ionogram Scaling Third Version., Radio Research Laboratory, Ministry of Posts and Telecommunications, 1987 